\title{
Identification of relaxins in porcine follicular fluid and in the ovary of the immature sow*
}

\author{
D. Matsumoto and W. A. Chamley $\dagger$ \\ Pacific Biomedical Research Centre, University of Hawaii, Honolulu, Hawaii 96826, U.S.A.
}

\begin{abstract}
Summary. Relaxin was measured by radioimmunoassay in follicular fluid from sows which were of different reproductive states. In non-pregnant animals, follicular fluid relaxin values ranged from 0.23 to $666 \mathrm{ng} / \mathrm{ml}$. For pregnant animals the range was $172.6-32707 \mathrm{ng} / \mathrm{ml}$ and for sows with polycystic ovaries this range was $5.0-2800$ $\mathrm{ng} / \mathrm{ml}$. For polycystic ovaries only there was a correlation $(r=0.74)$ between the diameter of the follicle and relaxin concentration in the respective fluid. Gel filtration of follicular fluid from a pregnant sow or one with polycystic ovaries revealed 3 species of relaxin, of molecular weights 27500,19000 and 6000 . Relaxin was extracted from $1 \mathrm{~kg}$ of ovaries collected from prepubertal pigs and gel filtration studies indicated the presence of large molecular weight species in addition to a molecule of approximately 6000 . These experiments suggest that the corpus luteum is not the sole source of relaxin in the pig.
\end{abstract}

\section{Introduction}

Since its discovery by Hisaw (1926), relaxin has been considered to be a hormone which was primarily associated with pregnancy (Hall, 1960; Belt, Anderson, Cavazos \& Melampy, 1971), and the ovary of the pregnant sow has been considered as a rich source of relaxin (Fevold, Hisaw \& Meyer, 1930; Griss, Keck, Engelhorn \& Tuppy, 1967; Belt et al., 1971). Many investigators considered that this hormone was solely a product of the corpus luteum (Belt et al., 1971; Anderson, Ford, Melampy \& Cox, 1973), but isolation studies of pregnant sow ovaries have indicated that relaxin can exhibit microheterogeneity (Sherwood \& O'Byrne, 1974). To date, two structures have been proposed for porcine relaxin with a molecular weight of approximately 6300 (Schwabe \& McDonald, 1976; Schwabe, McDonald \& Steinetz, 1977; James, Niall, Kwok \& Bryant-Greenwood, 1977).

This paper reports measurements of immunoactive relaxin in porcine follicular fluid, and the isolation and partial characterization of this material from follicular fluid and from ovaries of non-pregnant prepubertal sows.

\section{Materials and Methods}

\section{Collection of follicular fluid}

Sow ovaries were collected from a slaughterhouse and classified, on the basis of gross morphology and the contents of the uterus, as (1) from pregnant sows, (2) polycystic, (3) with active corpora lutea and from non-pregnant sows, (4) with corpora albicantia and from nonpregnant sows, or (5) from prepubertal sows.

* Reprint requests to Dr W. A. Chamley.

† Present address: Animal Research Institute, Werribee, Vic. 3030, Australia. 
Follicle diameters were measured using vernier callipers and then the follicular contents were aspirated using a small syringe. Samples were then centrifuged and the follicular fluid was aspirated and stored at $-20^{\circ} \mathrm{C}$. With some ovaries, the contents of several follicles were pooled and a mean follicular diameter was calculated. Since mating histories were available for the pregnant sows, it was possible to subdivide the samples into those from sows $<50$ days pregnant and $>90$ days pregnant.

\section{Gel filtration of follicular fluid}

Sufficient follicular fluid was collected from the ovary of 1 pregnant sow and from ovaries with polycystic follicles to provide two samples of follicular fluid for gel filtration studies. These samples had relaxin concentrations of 22.7 and $1.57 \mu \mathrm{g} / \mathrm{ml}$ respectively as measured by radioimmunoassay (see below). An aliquot of each $(0.75 \mathrm{ml}$ fluid from polycystic ovaries, $0.75 \mathrm{ml}$ of 1:100 diluted fluid from the pregnant sow) was chromatographed on Sephadex G-50 (superfine) using a $1.5 \times 85 \mathrm{~cm}$ column. The column was eluted with $0.05 \mathrm{M}$-phosphate-buffered saline containing $1 \%$ fetal calf serum and $0.02 \%$ sodium azide. Eluate fractions $(2.0 \mathrm{ml})$ were collected from the column and relaxin was measured in an aliquot from every second fraction.

\section{Isolation and gel filtration of relaxin}

Approximately $1 \mathrm{~kg}$ ovaries was collected from immature sows. Such ovaries contained no active corpora lutea or corpora albicantia. These ovaries were minced and processed for relaxin isolation according to the method of Sherwood \& O'Byrne (1974). The crude relaxin extract which was obtained as a dried powder was then run on a Sephadex G-50 (fine) column measuring $6.5 \times 1114 \mathrm{~cm}$. The column was eluted with $0.2 \mathrm{M}$-ammonium acetate buffer, $\mathrm{pH}$ 6.8 , and $10 \mathrm{ml}$ fractions were collected. Aliquots from every second fraction were subsequently assayed for relaxin.

\section{Radioimmunoassay}

The assay for measurement of relaxin in porcine follicular fluid and in chromatographed extract of ovaries from immature sows was the same as that described for measurement of relaxin in porcine plasma (Afele, Bryant-Greenwood, Chamley \& Dax, 1979). Relaxin was purified from freshly frozen pregnant sow ovaries using the procedures described by Sherwood \& O'Byrne (1974). This material corresponded to the peptide designated as CM-a' by Sherwood $\&$ O'Byrne (1974) and it had a potency of $2.87 \times$ NIH-R-P1 $(442 \mathrm{GPU} / \mathrm{mg})$ when measured in the mouse interpubic ligament bioassay (Steinetz et al., 1960).

An antiserum to $\mathrm{CM}-\mathrm{a}^{\prime}$ was raised in one rabbit using the immunization method described by Vaitukatis, Robbins, Neischlag \& Ross (1971). This antiserum was used in the assay at a final dilution of $1: 12000$ (diluted with $10 \% \mathrm{v} / \mathrm{v}$ horse serum in $0.05 \mathrm{M}$-barbitone buffer, $\mathrm{pH} 8.6$ ), and it showed no cross-reaction with porcine FSH (NIH-FSH-P1), porcine prolactin (Upjohn; Lot No. 9809SHE-19.4) or porcine insulin at concentrations to $1 \mu \mathrm{g} / \mathrm{ml}$. Porcine proinsulin caused some inhibition of binding at this concentration.

$\mathrm{CM}-\mathrm{a}^{\prime}$ was used as the standard and also for iodination. ${ }^{125}$ I-labelled succinylated relaxin was prepared by the method of Bolton \& Hunter (1973) as modified by McMurtry, Kwok \& Bryant-Greenwood (1978). In this procedure, CM-a' $(20 \mu \mathrm{g})$ was reacted with 3 ( $p$-hydroxylphenyl) propionic acid, $N$-hydroxysuccinimidyl ester (TAGIT: Calbiochem) $(4 \mu \mathrm{g}$ in $20 \mu \mathrm{l}$ benzene). After reaction of half of this succinylated relaxin with ${ }^{125} \mathrm{I}$, separation of ${ }^{125} \mathrm{I}$-labelled succinylated relaxin from unreacted succinamide ester and from free ${ }^{125}{ }^{2}$ was achieved using a Sephadex G-25 column $(25 \mathrm{~cm} \times 1.0 \mathrm{~cm}$ diameter) presaturated with $0.05 \%$ gelatin in $0.05 \mathrm{M}$ sodium phosphate buffer, $\mathrm{pH}$ 7.5. ${ }^{125}$ I-labelled hormone suitable for use in the radioimmuno- 
assay was diluted to a concentration of $1 \mathrm{ng} / \mathrm{ml}$ using 0.05 M-barbitone buffer, $\mathrm{pH} 8.6$, containing $0.5 \mathrm{mg}$ bovine gamma globulin $/ \mathrm{ml}$.

Follicular fluid samples were run in each assay at 8 serial dilutions and, when concentrations were very high, the samples were appropriately diluted with horse serum in $0.05 \mathrm{M}$ barbitone buffer, pH $8.6(1: 2 \mathrm{v} / \mathrm{v})$. Eluates from the Sephadex G-50 column were not diluted before assay. In all assays, non-specific binding was $<5 \%$ and the limit of sensitivity, representing the mass of unlabelled hormone which would cause a reduction in binding in excess of twice the standard deviation of counts bound at the zero point, was $200 \mathrm{pg} / \mathrm{ml}$. In each assay run, an aliquot of follicular fluid was included from a pool which had been collected for use as an internal standard. Relaxin concentration for this pool measured in 5 assays was $27.2 \pm 3.7$ (s.d.) $\mathrm{ng} / \mathrm{ml}$.

\section{Results}

For the non-pregnant animals the diameters of those follicles aspirated were in the range $3.8-$ $13.0 \mathrm{~mm}$ while the diameters of the polycystic follicles and follicles from ovaries of pregnant sows were in the range $10 \cdot 0-27.0 \mathrm{~mm}$ and $3.0-10.4 \mathrm{~mm}$ respectively. Relaxin was detected in 34 of the 38 samples assayed (Text-fig. 1).

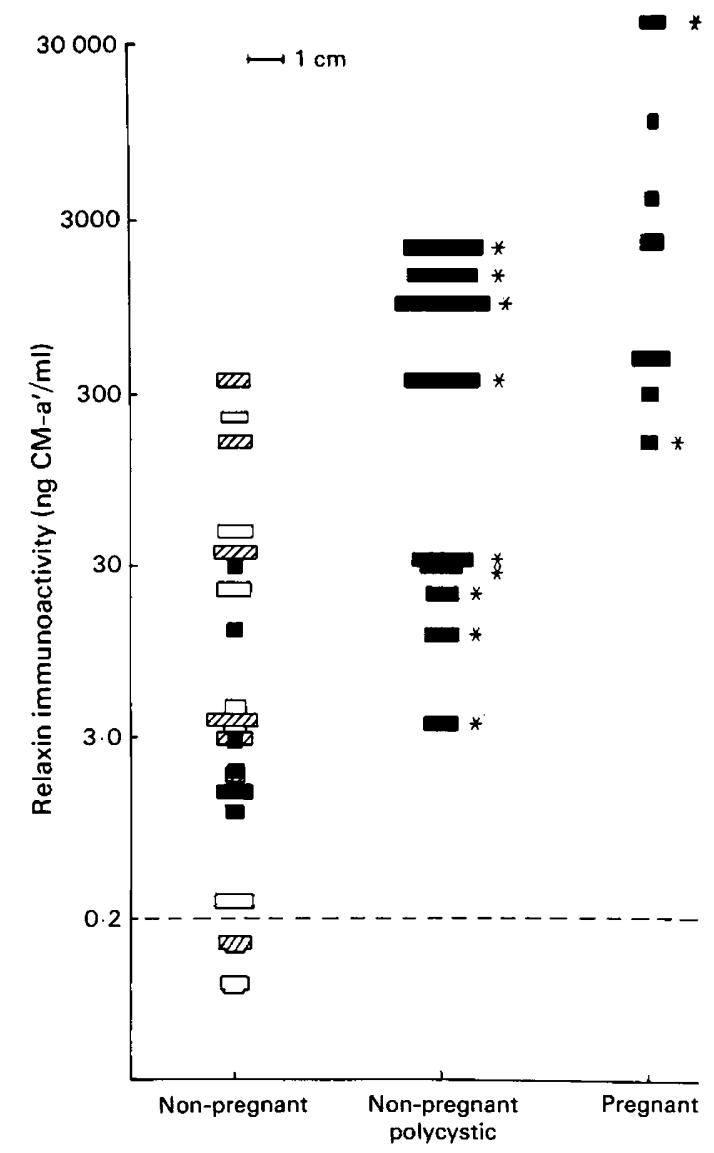

Text-fig. 1. The distribution of relaxin concentrations in follicular fluid from sows of different categories. Each bar represents the diameter of a single follicle (*) or the mean diameter for a pool of follicular fluid. The dotted line represents the lower limit of detection. Open bars represent ovaries without corpora lutea while hatched and solid bars represent ovaries with corpora albicantia and active corpora lutea respectively. 
All of the ovaries $(\mathrm{N}=9)$ considered to be polycystic contained active corpora lutea and macroscopic evidence of luteinization of these was not evident: relaxin concentrations ranged from 5.0 to $2800 \mathrm{ng} / \mathrm{ml}$. The concentrations in the ovaries from pregnant sows $(\mathrm{N}=7)$ were $127.6-32707 \mathrm{ng} / \mathrm{ml}$ but there was no relationship between relaxin concentration and stage of pregnancy. The range of relaxin concentrations in fluid from polycystic follicles was 3.4-2253 $\mathrm{ng} / \mathrm{ml}$. There was a relationship between relaxin concentration and follicle diameter for this group only, given by the regression equation $y=854.3 x+925.6(r=0.74)$. For this group, mean follicle diameter and mean relaxin concentration were greater than those of non-pregnant sows (Table 1).

When follicular fluid from pregnant sows or sows with polycystic ovaries was chromatographed on Sephadex G-50, 3 peaks of relaxin immunoactivity were detected (Text-fig. 2). On the basis of the calibration data which had been determined for this column, the molecular weights of material eluting approximately between 50 and $60 \mathrm{ml}, 60$ and $75 \mathrm{ml}$ and 90 and 110 $\mathrm{ml}$ were 27500,19000 and 6000 respectively.

Since relaxin was detected in follicular fluid from some sows which, on the basis of their ovarian morphology, had never ovulated, it was decided to attempt to isolate relaxin from $1 \mathrm{~kg}$ of such ovaries using the method of Sherwood \& O'Byrne (1974). As shown in Text-fig. 3,

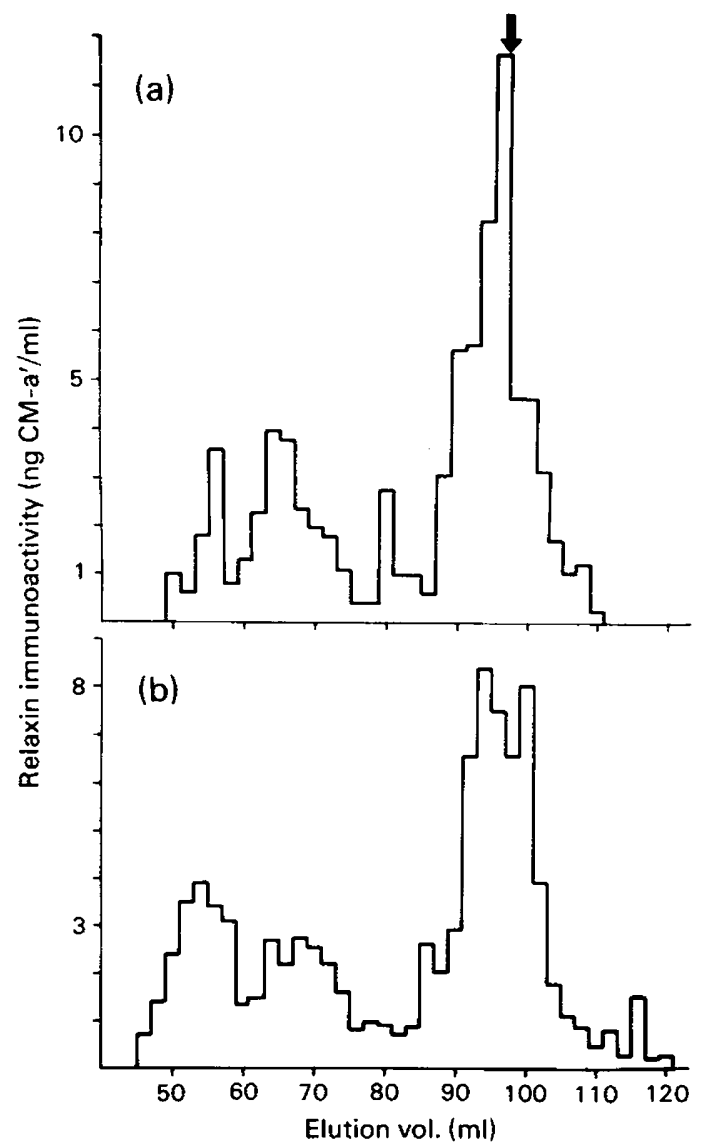

Text-fig. 2. Profiles of relaxin immunoactivity of follicular fluid from (a) a pregnant sow and (b) a sow with polycystic ovaries. Follicular fluid samples were chromatographed on a calibrated Sephadex G-50 (superfine) column using 0.05 M-phosphate-buffered saline containing $1 \%$ fetal calf serum and $0.02 \%$ sodium azide at $\mathrm{pH} 7 \cdot 5$. The arrow indicates the elution point of $\mathrm{CM}-\mathrm{a}^{\prime}$. 
Table 1. Mean \pm s.e.m. follicle diameters and relaxin concentrations in follicular fluid from non-pregnant sows or those with polycystic ovaries

\begin{tabular}{lrrr}
\hline & \multicolumn{2}{c}{ Cystic follicles } & \\
\cline { 2 - 3 } & \multicolumn{1}{c}{ Absent } & Present & Significance \\
\hline $\begin{array}{l}\text { Follicle diam. (mm) } \\
\begin{array}{l}\text { Relaxin immunoactivity } \\
\text { (ng/ml) }\end{array}\end{array}$ & $8.3 \pm 2.9 \pm 13.2$ & $218.6 \pm 1.8$ & $P<0.02$ \\
\hline
\end{tabular}

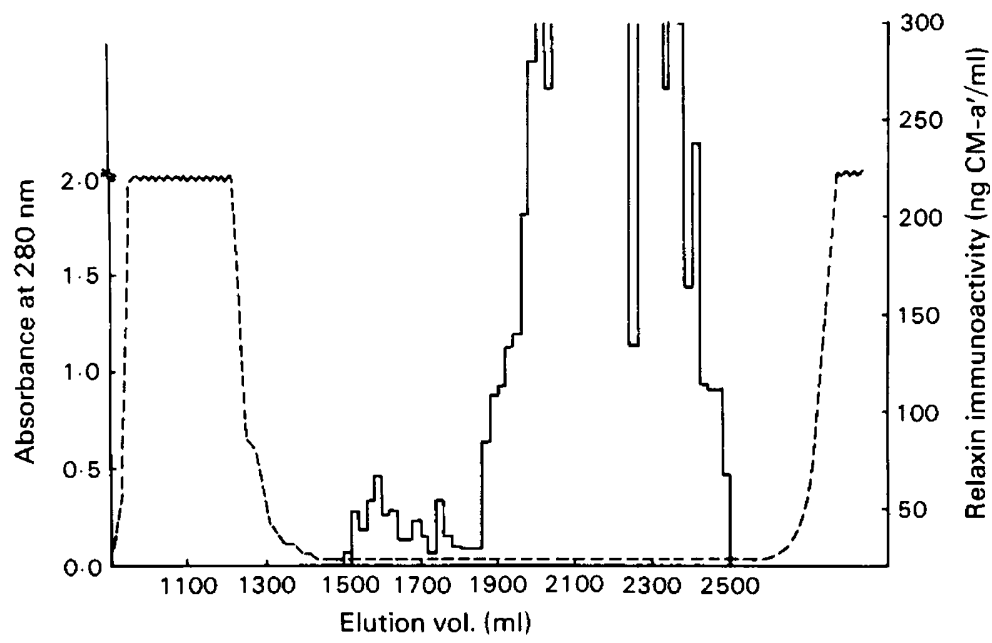

Text-fig. 3. Profile of relaxin immunoactivity for an $\mathrm{HCl}$-acetone extract of ovaries from prepubertal pigs. This crude relaxin preparation was prepared according to the method of Sherwood \& O'Byrne (1974) and was eluted on a Sephadex G-50 (fine) column $(6.5 \times 114 \mathrm{~cm})$ using 0.2 M-ammonium acetate buffer at $\mathrm{pH} 6 \cdot 8$.

relaxin activity was detectable after the crude extract from these ovaries had been run on Sephadex G-50. Most of the relaxin immunoactivity was eluted in a volume (1900-2500 ml) which corresponded to relaxin with a molecular weight of 6300; however, the presence of larger molecular weight species was also indicated by the detection of relaxin immunoactivity in a volume between 1500 and $1800 \mathrm{ml}$ (see Text-fig. 3).

\section{Discussion}

These studies indicate that, in the pig, there is an extra-luteal source of at least 3 immunoreactive, relaxin-like peptides. This conclusion was reached after relaxin was found by radioimmunoassay to be present in follicular fluid from the ovaries of sows which were pregnant or non-pregnant (mature or immature), and those with cystic follicles. Gel filtration studies indicated the presence of two relaxin-like peptides of greater molecular weight in addition to the native species. In the present studies, relaxin was detectable in an extract of whole ovaries taken from pigs which had never ovulated. Gel filtration of this extract indicated the presence of more than one species and the elution profile (Text-fig. 3) was comparable to those obtained for follicular fluid collected from pregnant sows and sows with polycystic ovaries (Text-fig. 2). This suggests that follicular fluid was the source of the relaxins found in the ovaries of immature sows.

In the pig, the corpus luteum of pregnancy has been considered to be a rich source of relaxin, although Anderson et al. (1973) found that relaxin was produced by the maintained corpus 
luteum of the hysterectomized sow. During pregnancy the corpus luteum must reach a certain age before synthesis and/or secretion of relaxin can take place (Sherwood, Martin, Chang \& Dziuk, 1977). Lemon \& Loir (1977) have separated and described two luteal cell types (based upon size) in the porcine corpus luteum but the question of whether this age requirement for relaxin synthesis and/or secretion represents a differentiation stage for one or both of these cell types remains to be answered.

The detection of additional large molecular weight species with relaxin immunoactivity in porcine follicular fluid and in an extract of immature sow ovaries was not surprising. A large molecular weight $(42000)$ molecule with biological activity has been isolated from a partly purified extract of pregnant sow ovaries (Frieden \& Yeh, 1977) and species of 19000,13000 and 10000 molecular weight have been extracted from fresh pregnant sow corpora lutea (Kwok, Chamley \& Bryant-Greenwood, 1978).

Polycystic ovaries are not uncommon in the sow and two major types of cystic conditions were described by Nalbandov (1952): some sows had multiple cysts of $2-5 \mathrm{~cm}$ in diameter in both ovaries while others had large numbers of small cysts up to $1.5 \mathrm{~cm}$ diameter. Both conditions were associated with temporary or permanent sterility. On the basis of the descriptions given by Nalbandov (1952) we consider that the polycystic ovaries in the present study contained cysts of the larger type. The polycystic ovaries contained relaxins in concentrations which were intermediate between those in ovaries from non-pregnant sows and pregnant sows. Since all polycystic ovaries contained corpora lutea which appeared to be functional, we were not able to rule out this gland as the source of the relaxins found. Wada \& Yuhara (1961) also found relaxin (using a bioassay) in the serum of cows with cystic ovaries and again luteal tissue was always present. At present we are unable to explain the presence of and/or role of relaxin in the polycystic ovarian condition. Polycystic follicles have been associated with a failure of ovulation in which elevated ACTH and adrenal activity are implicated (Liptrap, 1970). There is also evidence that this condition may be associated with failure of the uterine luteolytic mechanism (Close \& Liptrap, 1975). However, it is not known how relaxin synthesis and/or secretion is controlled and further study of the polycystic ovarian condition in the sow may provide an answer to these questions.

The follicular fluid of the sow has been much studied and is known to contain steroids (Hunter, Cook \& Baker, 1976), prostaglandins (Ainsworth, Baker \& Armstrong, 1975), protein hormones (Channing, 1972) and other large molecular weight proteins (McGaughey, 1975). In addition, a small peptide (approximately $2000 \mathrm{~mol}$. wt) which can inhibit oocyte maturation in vitro has been identified (Tsafriri, Pommerantz \& Channing, 1976). Our study represents the only one to identify and measure relaxin in porcine follicular fluid. The detection of relaxin in normal follicles unassociated with the presence of any luteal tissue raises important questions about the source of this relaxin and its functional role within the follicle. The granulosa cell does not appear to be the source because such cells did not produce relaxin when incubated with a wide range of concentrations of oestradiol-17ß, porcine prolactin, FSH and LH, or prostaglandins E-2 and F- $2 \alpha$ (W. A. Chamley, unpublished observations). So far, the thecal tissue has not been similarly studied.

Luteinization of porcine granulosa cells cultured in a chemically defined medium is enhanced by the addition of porcine insulin to the medium (Channing, Tsai \& Sachs, 1976). However, the concentrations of insulin in the follicular fluid from the 5 types of pig ovaries in this study were $<40 \mathrm{pg} / \mathrm{ml}$ (W. A. Chamley, unpublished observations). Insulin and relaxin are structurally very similar and it is possible that in the experiments of Channing et al. (1976) insulin was acting in the way that relaxin would have done had it been present.

We thank Ms S. Yamamoto for some technical help. This work was supported by the Haumana Biomedical Program, Grant No. 55064408125 (D.M.) and by the Lalor Foundation (W.A.C.). 


\section{References}

Afele, S., Bryant-Greenwood, G.D., Chamley, W.A. \& Dax, E.M. (1979) Plasma relaxin immunoactivity in the pig at parturition and during nuzzling and suckling. J. Reprod. Fert. 56, 451-457.

Ainsworth, L., Baker, R.D. \& Armstrong, D.T. (1975) Pre-ovulatory changes in follicular fluid prostaglandin F levels in swine. Prostaglandins 9, 915-925.

Anderson, L.L., Ford, J.J., Melampy, R.M. \& Cox, D.F. (1973) Relaxin in porcine corpora lutea during pregnancy and after hysterectomy. Am. J. Physiol. 225, 1215-1219.

Belt, W.D., Anderson, L.L., Cavazos, L.F. \& Melampy, R.M. (1971) Cytoplasmic granules and relaxin levels in porcine corpora lutea. Endocrinology 89, 1-10.

Bolton, A.E. \& Hunter, W.M. (1973) The labelling of proteins to high specific radioactivities by conjugation to a $\mathrm{I}^{125}$ containing acetylating agent. Biochem. J. 133, 529-539.

Channing, C.P. (1972) Factors involved in luteinization in vitro. In Proc. 4th Int. Congr. Endocrinology, pp. 914-919. Excerpta Medica (ICS No. 273), Amsterdam.

Channing, C.P., Tsai, V. \& Sachs, D. (1976) Role of insulin, thyroxin and cortisol in luteinization of porcine granulosa cells grown in chemically defined media. Biol. Reprod. 15, 235-247.

Close, R.W. \& Liptrap, R.M. (1975) Plasma progesterone levels in sows with induced cystic ovarian follicles. Res. Vet. Sci. 19, 28-34.

Fevold, H.L., Hisaw, F.L. \& Meyer, R.K. (1930) Isolation of the relaxative hormone on the corpus luteum. Proc. Soc. exp. Biol. Med. 27, 604-606.

Frieden, E.H. \& Yeh, L. (1977) Evidence for a "prorelaxin" in porcine relaxin concentrates. Proc. Soc. exp. Biol. Med. 154, 407-411.

Griss, G., Keck, J., Engelhorn, R. \& Tuppy, H. (1967) The isolation and purification of an ovarian polypeptide with uterine relaxing activity. Biochim. biophys. Acta 140, 45-54.

Hall, K. (1960) Relaxin. J. Reprod. Fert. 1, 368-384.

Hisaw, F.L. (1926) Experimental relaxation of the pubic ligament of the guinea pig. Proc. Soc. exp. Biol. Med. 23, 661-663.

Hunter, R.H.F., Cook, B. \& Baker, T.G. (1976) Dissociation of response to injected gonadotropin between the Graafian follicle and oocyte in pigs. Nature, Lond. 260, 156-158.

James, R., Niall, H., Kwok, S. \& Bryant-Greenwood, G.D. (1977) Primary structure of porcine relaxin: homology with insulin and related growth factors. Nature, Lond. 267, 544-546.
Kwok, S.C.M., Chamley, W.A. \& Bryant-Greenwood, G.D. (1978) High molecular weight forms of relaxin in pregnant sow ovaries. Biochem. Biophys. Res. Commun. 82, 997-1005.

Lemon, M. \& Loir, M. (1977) Steroid release in vitro by two luteal cell types in the corpus luteum of the pregnant sow. J. Endocr. 72, 351-359.

Liptrap, R.M. (1970) Effect of corticotrophin and corticosteroids on oestrus, ovulation and oestrogen excretion in the sow. J. Endocr. 47, 197-205.

McGaughey, R.W. (1975) A comparison of the fluids from small and large ovarian follicles of the pig. Biol. Reprod. 13, 147-153.

McMurtry, P.J., Kwok, S.C.M. \& Bryant-Greenwood, G.D. (1978) Target tissues for relaxin identified in vitro with ${ }^{125} \mathrm{I}$-labelled porcine relaxin. J. Reprod. Fert. 53, 209-216.

Nalbandov, A.V. (1952) Anatomic and endocrine causes of sterility in female swine. Fert. Steril. 3, 100-114.

Schwabe, C. \& McDonald, J.K. (1976) The primary structure of the A chain of porcine relaxin. Biochem. Biophys. Res. Commun. 70, 397-405.

Schwabe, C., McDonald, J.K. \& Steinetz, B.G. (1977) The primary structure of the $B$ chain of porcine relaxin. Biochem. Biophys. Res. Commun. 75, 503510.

Sherwood, C.D. \& O'Byrne, E.M. (1974) Purification and characterisation of porcine relaxin. Archs Biochem. Biophys. 160, 185-196.

Sherwood, O.D., Martin, P.A., Chang, C.C. \& Dziuk, P.J. (1977) Plasma relaxin levels in pigs with corpora lutea induced during late pregnancy. Biol. Reprod. 17, 97-100.

Steinetz, B.G., Beach, V.L., Kroc, R.L., Stasilli, N., Nussbaum, R.E., Nemith, P.J. \& Dun, R.K. (1960) Bioassays of relaxin using a reference standard: a simple and reliable method utilizing direct measure ment of interpubic ligament formation in mice. Endocrinology. 67, 102-115.

Tsafriri, A., Pommerantz, S.H. \& Channing, C.P. (1976) Inhibition of oocyte maturation by porcine follicular fluid. Partial characterization of the inhibitor. Biol. Reprod. 14, 511-516.

Vaitukatis, J.L., Robbins, J.B., Nieschlag, E. \& Ross, G.T. (1971) A method for producing specific antisera with small doses of immunogen. J. clin. Endocr. Metab. 33, 988-991.

Wada, H. \& Yuhara, M. (1961) Concentration of relaxin in the blood serum of pregnant cow and cow with ovarian cyst. Laboratory of Animal Husbandry, College of Agriculture, Kyoto University. 